\title{
Comparison of modifiable health behaviours between persons with and without cancer: the Multiethnic Cohort
}

\author{
Nicholas J Ollberding ${ }^{1, *}$, Gertraud Maskarinec ${ }^{1}$, Lynne R Wilkens ${ }^{1}$, \\ Brian E Henderson ${ }^{2}$ and Laurence $N$ Kolonel ${ }^{1}$ \\ 'Epidemiology Program, Cancer Research Center of Hawaii, University of Hawaii, Honolulu, HI 96813, USA: \\ ${ }^{2}$ Department of Preventive Medicine, Keck School of Medicine, University of Southern California, Los Angeles, \\ CA, USA
}

Submitted 8 June 2010: Accepted 7 0ctober 2010: First published online 5 January 2011

\begin{abstract}
Objective: To compare the prevalence of modifiable risk factors for cancer and other chronic diseases between adult cancer survivors and persons with no history of cancer.

Design: Cross-sectional.

Setting: Population-based sample residing in California and Hawaii.

Subjects: A total of 177003 men and women aged 45-75 years who participated in the Multiethnic Cohort Study (MEC). Logistic regression was used to examine adherence to recommendations regarding modifiable risk factors among cancer survivors ( $n$ 16346) when compared with cohort members with no history of cancer ( $n$ 160657).

Results: Cancer survivors were less likely than cohort members with no history of cancer to meet recommendations specified in the World Cancer Research Fund/ American Institute for Cancer Research (WCRF/AICR) 2007 report (OR = 0.97; 95\% CI 0.96, 0.99). No difference between groups was seen for adherence to dietary recommendations alone $(\mathrm{OR}=0.99$; $95 \%$ CI $0.98,1 \cdot 01)$. Site-specific analyses showed that results for colorectal cancer were similar to those for all cancers combined, but survivors of breast (OR $=1 \cdot 04 ; 95 \% \mathrm{CI} 1 \cdot 02,1 \cdot 07)$ and prostate $(\mathrm{OR}=1 \cdot 04 ; 95 \% \mathrm{CI} 1 \cdot 01,1 \cdot 07)$ cancer were more likely to meet dietary recommendations. Latino survivors were less likely to adhere to WCRF/AICR recommendations than Latino controls; however, differences across ethnic groups were not significant $\left(P_{\text {interaction }}=0 \cdot 64\right)$.

Conclusions: The modest differences found between adult cancer survivors and persons with no history of cancer suggest that a diagnosis of cancer in itself may not be associated with improvements in health behaviours related to cancer and other chronic diseases.
\end{abstract}

\author{
Keywords \\ Cancer survivors \\ Health behaviours \\ Diet and cancer
}

Owing to advances in cancer treatment and screening, there are now over 10 million cancer survivors in the $\mathrm{USA}^{(1)}$. Given the ageing of the US population and estimates of 5-year survival as high as $64 \%{ }^{(1)}$, this number is expected to continue to increase. Cancer survivors are at increased risk for recurrent disease or second primary malignancies, as well as for higher mortality from other chronic diseases including CVD, diabetes and osteoporosis $^{(2)}$; they also have higher mortality rates from noncancer causes than does the general population ${ }^{(3)}$.

As the number of cancer survivors continues to grow, tertiary prevention strategies aimed at reducing disease burden in this population are becoming increasingly important. Because of limited evidence on health behaviours and cancer survival, recommendations for cancer survivors are based primarily on cancer prevention guidelines for the general population ${ }^{(4)}$. Poor diet and physical inactivity operating independently or through obesity-mediated pathways, as well as alcohol consumption and smoking, form the foundation for cancer prevention recommendations with respect to modifiable health behaviours ${ }^{(4-6)}$. On the basis of estimates that approximately two-thirds of all cancer deaths may be attributable to tobacco use, poor diet, physical inactivity and excess weight $^{(7)}$, improvements in these behaviours after a diagnosis of cancer may have a significant impact on the overall health and life expectancy of cancer survivors.

Better information regarding the extent to which cancer survivors are altering their health behaviours following the diagnosis of cancer can provide a basis for targeted programmes to reduce their long-term morbidity and mortality. Previous studies have found that survivors 
report improvements in modifiable health behaviours ${ }^{(8-12)}$ (for a complete review, see Demark-Wahnefried et al. ${ }^{(2)}$ ); although prevalence studies cannot directly assess behavioural changes among cancer survivors, data from national health surveys have failed to show differences in health behaviours between cancer survivors and the general population ${ }^{(13-16)}$. Therefore, the purpose of the present study was to examine whether modifiable health behaviours differed between cancer survivors and participants with no history of cancer at baseline in the Multiethnic Cohort Study (MEC) and whether associations remained consistent across cancer sites or among ethnic groups. Specifically, differences in dietary intake, physical activity, BMI, smoking and alcohol consumption were examined. Recommendations by the World Cancer Research Fund/American Institute for Cancer Research (WCRF/AICR) $2007^{(4)}$ for reducing the risk of cancer associated with nutrition and physical activity were compared for behaviours addressed in the report. On the basis of the findings of previous reports, we hypothesized that there would be few differences between cancer survivors and participants reporting no history of cancer with respect to the health behaviours examined. A lack of previous data for several ethnic groups examined in the present study precluded any a priori hypotheses regarding ethnic differences in health behaviours of cancer survivors.

\section{Methods}

\section{Study population}

The MEC is a longitudinal study designed to investigate the role of lifestyle and dietary factors in the aetiology of cancer in a multiethnic population of US adults and has been described previously in detail ${ }^{(17)}$. Briefly, from 1993 to 1996, 215831 men and women between 45 and 75 years of age at recruitment and residing in Hawaii or California consented to participate in the study by completing a baseline questionnaire. Participants were comprised primarily of five main self-reported ethnic groups - African Americans, Japanese Americans, Latinos, Native Hawaiians and Whites - and were recruited through drivers' licence records, voter registration lists and Health Care Financing Administration files to obtain adequate and representative samples for each ethnic group. Participants reporting mixed ethnicity were classified using the following hierarchy: African American, Native Hawaiian, Latino, Japanese American, White and others. More than 95\% of all non-Hawaiians reported only one ethnic group. At cohort entry, participants completed a twenty-six-page questionnaire with questions pertaining to demographic characteristics, anthropometrics, medical history, family history, reproductive history, cancer screening practices, occupational history, physical activity and diet. The study was approved by the Institutional Review Boards of the University of Hawaii and the University of Southern California.
For the present analysis, participants who were not classified into one of the five main ethnic groups ( $n$ 13994), who reported implausible dietary values of $3 \mathrm{sD}$ from a truncated normal distribution using the middle $80 \%$ of logged energy values and $3.5 \mathrm{sD}$ for logged fats, proteins and carbohydrates within each sex-ethnic group ( $n$ 8265) or had missing covariate data ( $n$ 16 569) were excluded. Therefore, data on 177003 participants were available for analysis.

\section{Measures}

\section{Identification of cancer survivors}

Cancer survivors for the present study were identified either through the baseline questionnaire or through the tumour registry linkage. In the baseline questionnaire, participants were asked whether they had ever been told by a doctor that they had cancer of the stomach, breast, prostate, cervix, uterus, colon or rectum, melanoma, other skin or other cancers not listed. Participants were considered to be cancer survivors if they answered 'yes' to having cancer at any site other than non-melanoma skin cancer in the baseline questionnaire or if they were identified as a case before cohort entry through linkage to the Surveillance, Epidemiology, and End Results (SEER) cancer registries for Hawaii (Hawaii Tumor Registry) and California (the Cancer Surveillance Program for Los Angeles County, California State Cancer Registry). Of participants included in the present analysis, 8362 reported a history of cancer and were registry confirmed; 2600 additional cases were found in the registries, whereas 5384 self-reported cases could not be linked to the two statewide registries. In addition to possible falsepositive reports, the latter number could reflect cases diagnosed outside Hawaii and California. Only 33\% of registry cases not self-reported were among the specific sites listed on the survey, despite the high prevalence of these cancers. Because no differences by source of cancer information were observed in preliminary analyses, all results included non-duplicative cases identified either by questionnaire or by tumour registry.

\section{Dietary assessment}

Dietary intake information was obtained for the MEC using a Quantitative FFQ (QFFQ) designed for use in this multiethnic population. Food items included in the questionnaire were those identified from $3 \mathrm{~d}$ measured food records as the minimum set that could explain $\geq 85 \%$ of nutrient intake for nutrients of interest in each ethnic group ${ }^{(17)}$. Foods traditionally consumed by ethnic populations targeted in the study were added to the questionnaire regardless of their contribution to nutrient intake. A calibration study of the QFFQ was conducted using three $24 \mathrm{~h}$ recalls from a random subsample of participants selected within sex-ethnic groups and revealed a high correlation between the QFFQ and $24 \mathrm{~h}$ recalls for energy-adjusted nutrients ${ }^{(18)}$. Dietary values 
were computed from the QFFQ using the food composition database designed and maintained by the Cancer Research Center of Hawaii ${ }^{(17)}$.

\section{Demographic characteristics and health behaviours}

Demographic information on age, sex, ethnicity and educational attainment was collected through the baseline questionnaire. Self-reported height and weight were used to calculate BMI $\left(\mathrm{kg} / \mathrm{m}^{2}\right)$. Table 1 shows how the recommendations were operationalized for the present study. Smoking status was assessed by asking participants if they had ever smoked more than twenty packs of cigarettes in their lifetime. Those reporting 'no' were considered to be never smokers; those reporting 'yes, but I quit smoking' were former smokers; and those reporting 'yes, and I currently smoke' were classified as current smokers. A BMI within the normal range $\left(18 \cdot 5-24 \cdot 9 \mathrm{~kg} / \mathrm{m}^{2}\right)$ was considered in agreement with the recommendation, although the WCRF/AICR advice is to 'be as lean as possible within the normal range of body weight ${ }^{(4)}$. Women who reported consuming one or less and men who reported consuming two or less alcoholic beverages per day were classified as meeting the WCRF/AICR recommendation for alcohol consumption. Physical activity was estimated from baseline questions on work and leisure-time physical activity and sedentary activities; engaging in at least an average of 30 min of moderate or vigorous physical activity per day was considered adequate. Values for dietary variables were obtained from the QFFQ and dichotomized to reflect adherence to the WCRF/AICR recommendations whenever possible or to be in agreement with the 2005 Dietary
Guidelines for Americans ${ }^{(19)}$. Participants reporting intakes of $\geq 400 \mathrm{~g}$ of fruit and vegetables per day, $<500 \mathrm{~g}$ of red meat per week, $<2.4 \mathrm{~g}$ of $\mathrm{Na}$ per day, $\geq 25 \mathrm{~g}$ of dietary fibre per day, $<30 \%$ of total energy from fat and $<10 \%$ of total energy from saturated fat were considered as meeting recommendations.

Two index scores were created from questionnaire variables. For adherence to the WCRF/AICR recommendations specified in the 2007 report $^{(4)}$, we assigned one point for meeting recommendations that could be operationalized (BMI, physical activity, alcohol consumption, fruit and vegetables, red meat and $\mathrm{Na}$ ). We then added the values for each participant, allowing for a maximum possible score of 6 . To assess whether a history of cancer had a unique impact on dietary behaviours, an index score was created to examine adherence to dietary recommendations for several food items (fruit and vegetables, red meat, $\mathrm{Na}$, fibre, total fat) specifically addressed in the WCRF/AICR 2007 report or listed as having a 'probable' or 'suggestive' role in the aetiology of cancer ${ }^{(4)}$. Saturated fat intake was also included in the dietary index score, given its consistent association with CVD. One point was assigned for meeting each dietary recommendation and the values were then added, allowing for a maximum possible score of 6 .

\section{Statistical analysis}

Descriptive statistics were calculated for demographic characteristics, BMI, smoking status, alcohol consumption, physical activity and diet for cancer survivors and participants with no history of cancer. Age, sex, ethnicity and educational level were found to differ by cancer

Table 1 Recommendations for health behaviours examined in the present study

\begin{tabular}{|c|c|c|}
\hline Health behaviour & Recommendation & Study construct \\
\hline Smoking & $\begin{array}{l}\text { The panel also emphasizes the importance of not } \\
\text { smoking and avoiding exposure to tobacco smoke* }\end{array}$ & Current smoking \\
\hline BMI $\left(\mathrm{kg} / \mathrm{m}^{2}\right)$ & $\begin{array}{l}\text { Maintain body weight within the normal range from the } \\
\text { age of } 21 \text { years }^{*}\end{array}$ & BMI $\left(18 \cdot 5-24 \cdot 9 \mathrm{~kg} / \mathrm{m}^{2}\right)$ \\
\hline Alcohol consumption & $\begin{array}{l}\text { If alcoholic drinks are consumed, limit consumption to } \\
\text { no more than two drinks per day for men and one } \\
\text { drink per day for women* }\end{array}$ & Meeting WCRF/AICR recommendation \\
\hline Physical activity & $\begin{array}{l}\text { Be moderately physically active, equivalent to brisk } \\
\text { walking, for at least } 30 \mathrm{~min} / \mathrm{d} \\
\text { As fitness improves, aim for } \geq 60 \text { min of moderate, or } \\
\text { for } \geq 30 \text { min of vigorous, physical activity per day* }\end{array}$ & Meeting WCRF/AICR recommendation \\
\hline Fruit and vegetable intake & $\begin{array}{l}\text { Eat at least five portions per servings of a variety of } \\
\text { non-starchy vegetables and of fruits per day }{ }^{*}\end{array}$ & Fruit and vegetables $(\geq 400 \mathrm{~g} / \mathrm{d})$ \\
\hline Red meat intake & $\begin{array}{l}\text { People who eat red meat to consume }<500 \mathrm{~g} / \text { week } \\
\text { very little if any amount is to be processed }\end{array}$ & Red meat (<500 g/week) \\
\hline $\mathrm{Na}$ intake & $\begin{array}{l}\text { Limit consumption of processed foods with added salt } \\
\text { to ensure an intake of }<2 \cdot 4 \mathrm{~g} \mathrm{Na} / \mathrm{d}^{*}\end{array}$ & $\mathrm{Na}(<2 \cdot 4 \mathrm{~g} / \mathrm{d})$ \\
\hline Dietary fibre & $\begin{array}{l}\text { Relatively unprocessed cereals (grains) and/or pulses } \\
\text { (legumes) and other foods that are a natural source } \\
\text { of dietary fibre to contribute to a population average } \\
\text { of at least } 25 \mathrm{~g} \text { of NSP per day* }\end{array}$ & Dietary fibre $(\geq 25 \mathrm{~g} / \mathrm{d})$ \\
\hline Total fat & Keep total fat intake between $20 \%$ and $35 \%$ of energy $t$ & $\%$ Energy from fat $(<30 \%)$ \\
\hline Saturated fat & Consume $<10 \%$ of energy from SFAt & $\%$ Energy from saturated fat $(<10 \%)$ \\
\hline
\end{tabular}

WCRF/AICR, World Cancer Research Fund/American Institute for Cancer Research.

*WCRF/AICR 2007 report Food, Nutrition, Physical Activity, and the Prevention of Cancer: A Global Perspective(4).

tDietary Guidelines for Americans $2005^{(19)}$. 
status and were therefore included as covariates in regression models. BMI was also found to differ and was included only in models of specific behaviours, as it was a component of the WCRF/AICR score and did not affect diet score results. Unconditional multivariable logistic regression was used to obtain OR and 95\% CI for cancer survivors as compared with participants with no history of cancer. Because regression models indicated that behaviours did not differ by time from diagnosis, cancer status source (questionnaire or registry) or by age in decades, results stratified on these subgroups are not presented. The heterogeneity of effect of health behaviours across ethnic groups was tested by a Wald test of the crossproduct terms between ethnicity and behaviour, with a $P$ value of $\leq 0.05$ being considered as significant. All data analyses were performed using the SAS statistical software package version 9.2 (SAS Institute Inc., Cary, NC, USA).

\section{Results}

Through the questionnaire and tumour registry linkage, 16346 unique prevalent cases of cancer were identified at baseline (Table 2). Unadjusted results showed that cancer survivors reported meeting a greater number of WCRF/AICR and dietary recommendations than did participants with no history of cancer (Table 3). Survivors were older, more often female and of African-American or white ethnicity, and were less often reported to be current smokers or to meet physical activity recommendations. The proportion of participants meeting dietary recommendations was similar for cancer survivors and for participants with no history of cancer (Table 3).

Adjusted for age, sex, ethnicity and educational attainment, survivors of cancer at any site were less likely to meet WCRF/AICR recommendations, although not to differ on meeting dietary recommendations alone, than participants with no history of cancer (Table 4). Findings for survivors of colorectal cancer were similar to those of survivors of cancer at any site for adherence to both index scores; however, breast and prostate cancer survivors reported diets that were more likely to meet recommendations.

With regard to specific behaviours, survivors of cancer at any site were more likely to be underweight or former smokers, and less likely to meet the physical activity or saturated fat recommendations. Survivors of colorectal cancer were more likely to report being obese or former smokers and less likely to report meeting the physical activity recommendation. Breast cancer survivors were less likely to meet the recommendation regarding physical activity or to be a current smoker, but were more likely to meet recommendations regarding red meat, $\mathrm{Na}$, total fat and saturated fat intake. Interestingly, survivors of prostate cancer were less likely to be former or current smokers or to meet the physical activity recommendation, but more likely to meet the recommendations regarding alcohol and red meat consumption.
Table 2 Site of diagnosis for cancer survivors*

\begin{tabular}{lcc}
\hline Cancer site & $n$ & $\%$ \\
\hline Total & 16346 & $100 \cdot 0$ \\
Breast: females/males & $3436 / 24$ & $21 \cdot 0 / 0 \cdot 2$ \\
Prostate & 2407 & $14 \cdot 7$ \\
Melanoma & 1977 & $12 \cdot 1$ \\
Colorectum & 1741 & $10 \cdot 7$ \\
Cervix & 1525 & $9 \cdot 3$ \\
Endometrium & 1018 & $6 \cdot 2$ \\
Lung & 480 & $2 \cdot 9$ \\
Thyroid & 380 & $2 \cdot 3$ \\
Bladder & 331 & $2 \cdot 0$ \\
Stomach & 268 & $1 \cdot 6$ \\
Ovary & 250 & $1 \cdot 5$ \\
Kidney & 226 & $1 \cdot 4$ \\
Hodgkin's lymphoma & 127 & $0 \cdot 8$ \\
Non-Hodgkin's lymphoma & 88 & $0 \cdot 5$ \\
Leukaemia & 70 & $0 \cdot 4$ \\
Liver & 52 & $0 \cdot 3$ \\
Myeloma & 45 & $0 \cdot 3$ \\
Pancreas & 40 & $0 \cdot 2$ \\
Others & 1861 & $11 \cdot 4$ \\
\hline
\end{tabular}

${ }^{*}$ Case status obtained from the baseline questionnaire or tumour registry linkage.

African-American, Japanese-American, Native Hawaiian and white survivors of cancer at any site did not differ from participants with no history of cancer with regard to meeting WCRF/AICR or dietary recommendations (Table 5). However, Latino cancer survivors were less likely than their counterparts with no history of cancer to meet WCRF/AICR recommendations, although not the dietary recommendations alone. Tests of heterogeneity for specific behaviours showed differences among ethnic groups on smoking status, alcohol consumption, physical activity, dietary fibre and energy from fat $(P<0 \cdot 05)$. Japanese-American cancer survivors were the only group with a lower likelihood of current smoking and increased likelihood of consuming $\geq 25$ g of dietary fibre per day. White cancer survivors were the only ethnic group less likely to meet the recommendation regarding alcohol consumption, and AfricanAmerican survivors were the only ethnic group less likely to consume $<30 \%$ of energy from fat.

\section{Discussion}

In a cross-sectional analysis utilizing baseline data from the MEC, few differences were found between cancer survivors and participants with no history of cancer with respect to meeting recommendations regarding modifiable health behaviours that may reduce the risk of cancer and other chronic diseases. Survivors of cancer at any site and those of colorectal cancer were less likely to meet WCRF/AICR recommendations, whereas breast and prostate cancer survivors were more likely to meet dietary recommendations. However, the magnitude of these differences suggests that a diagnosis of cancer is not associated with meaningful differences in health behaviours 
Table 3 Baseline demographic characteristics and health behaviours of participants in the Multiethnic Cohort Study by history of cancer status

\begin{tabular}{|c|c|c|c|c|}
\hline & \multicolumn{2}{|c|}{ Cancer survivors } & \multicolumn{2}{|c|}{ No history of cancer } \\
\hline & $n$ & $\%$ & $n$ & $\%$ \\
\hline Total & 16346 & $100 \cdot 0$ & 160657 & $100 \cdot 0$ \\
\hline \multicolumn{5}{|l|}{ Demographics } \\
\hline \multicolumn{5}{|l|}{ Age at recruitment (years) } \\
\hline $45-54$ & 2981 & $18 \cdot 2$ & 55078 & $34 \cdot 3$ \\
\hline $55-64$ & 4736 & $29 \cdot 0$ & 54157 & $33 \cdot 7$ \\
\hline $65-75$ & 8629 & $52 \cdot 8$ & 51422 & $32 \cdot 0$ \\
\hline \multicolumn{5}{|l|}{ Sex } \\
\hline Male & 6766 & $41 \cdot 4$ & 74873 & $46 \cdot 6$ \\
\hline Female & 9580 & $58 \cdot 6$ & 85784 & $53 \cdot 4$ \\
\hline \multicolumn{5}{|l|}{ Race/ethnicity } \\
\hline African American & 3135 & $19 \cdot 2$ & 25841 & $16 \cdot 1$ \\
\hline Japanese American & 4152 & $25 \cdot 4$ & 47746 & $29 \cdot 7$ \\
\hline Latino & 2696 & $16 \cdot 5$ & 35278 & $22 \cdot 0$ \\
\hline Native Hawaiian & 1094 & $6 \cdot 7$ & 11980 & $7 \cdot 5$ \\
\hline White & 5269 & $32 \cdot 2$ & 39812 & $24 \cdot 8$ \\
\hline \multicolumn{5}{|l|}{ Education } \\
\hline$\leq 8$ th grade & 1495 & $9 \cdot 1$ & 15659 & $9 \cdot 7$ \\
\hline 9th-12th grade & 5731 & $35 \cdot 1$ & 52373 & $32 \cdot 6$ \\
\hline Some college or vocational & 4983 & $30 \cdot 5$ & 48302 & $30 \cdot 1$ \\
\hline College graduate & 4137 & $25 \cdot 3$ & 44323 & $27 \cdot 6$ \\
\hline \multicolumn{5}{|l|}{ BMI $\left(\mathrm{kg} / \mathrm{m}^{2}\right)$} \\
\hline Underweight & 439 & $2 \cdot 7$ & 2825 & $1 \cdot 8$ \\
\hline Normal weight & 6747 & $41 \cdot 3$ & 64012 & $39 \cdot 8$ \\
\hline Overweight & 5961 & $36 \cdot 5$ & 61877 & $38 \cdot 5$ \\
\hline Obese & 3199 & $19 \cdot 6$ & 31943 & $19 \cdot 9$ \\
\hline \multicolumn{5}{|l|}{ Health behaviours } \\
\hline \multicolumn{5}{|l|}{ Smoking status } \\
\hline Never smoker & 6718 & $41 \cdot 1$ & 70686 & $44 \cdot 0$ \\
\hline Former smoker & 7364 & $45 \cdot 1$ & 63825 & $39 \cdot 7$ \\
\hline Current smoker & 2264 & $13 \cdot 9$ & 26146 & $16 \cdot 3$ \\
\hline \multicolumn{5}{|l|}{ Alcohol consumption } \\
\hline Meets recommendation* & 14219 & $87 \cdot 0$ & 139718 & $87 \cdot 0$ \\
\hline \multicolumn{5}{|l|}{ Physical activity } \\
\hline Meets recommendationt & 9408 & $57 \cdot 6$ & 99766 & $62 \cdot 1$ \\
\hline \multicolumn{5}{|l|}{ Diet } \\
\hline Fruit and vegetables $(\geq 400 \mathrm{~g} / \mathrm{d})$ & 12194 & $74 \cdot 6$ & 117514 & $73 \cdot 2$ \\
\hline Red meat $(<500 \mathrm{~g} /$ week $)$ & 12211 & $74 \cdot 7$ & 112478 & $70 \cdot 0$ \\
\hline $\mathrm{Na}(<2 \cdot 4 \mathrm{~g} / \mathrm{d})$ & 5973 & $36 \cdot 5$ & 54021 & $33 \cdot 6$ \\
\hline Dietary fibre $(\geq 25 \mathrm{~g} / \mathrm{d})$ & 6644 & $40 \cdot 6$ & 64946 & $40 \cdot 4$ \\
\hline$\%$ Energy from fat $(<30 \%)$ & 8202 & $50 \cdot 2$ & 79000 & $49 \cdot 2$ \\
\hline \multirow[t]{2}{*}{$\%$ Energy from saturated fat $(<10 \%)$} & 11055 & $67 \cdot 6$ & 109066 & $67 \cdot 9$ \\
\hline & Mean & $95 \% \mathrm{Cl}$ & Mean & $95 \% \mathrm{Cl}$ \\
\hline WCRF/AICR recommendations met & $3 \cdot 72$ & $3 \cdot 70,3 \cdot 73$ & $3 \cdot 66$ & $3.65,3.66$ \\
\hline Dietary recommendations met $\ddagger$ & $3 \cdot 44$ & $3.42,3.47$ & $3 \cdot 34$ & $3 \cdot 34,3 \cdot 35$ \\
\hline
\end{tabular}

WCRF/AICR, World Cancer Research Fund/American Institute for Cancer Research.

${ }^{*}$ WCRF/AICR recommendation for those who choose to drink alcohol is $\leq 1$ drink/d for women and $\leq 2$ drinks/d for men.

tWCRF/AICR physical activity recommendation is to engage in at least $30 \mathrm{~min}$ of moderate or vigorous physical activity per day. ¥Max score is 6 .

in a large, multiethnic sample of older adults. It should be noted that the MEC was based on general population sampling and that participants were shown to be reasonably representative, on the basis of comparisons with US Census data ${ }^{(17)}$. Similarities between cancer survivors and participants with no history of cancer were found to be consistent across ethnic groups.

Although Latino survivors had the lowest likelihood of meeting WCRF/AICR recommendations compared with their controls, the differences by ethnic group were not significant. Differences between ethnic groups for meeting dietary recommendations were detected; although for no ethnic group did associations differ from unity.

Our findings that the prevalence of overweight and obesity, current smoking, alcohol consumption and diet was similar for cancer survivors and older adults with no history of cancer are generally consistent with those of previous studies ${ }^{(13-16)}$. Coups and Ostroff ${ }^{(13)}$ reported similar findings for diet, physical activity, alcohol consumption, current smoking and BMI in the 2000 National Health Interview Survey (NHIS). Bellizzi et $a l^{(14)}$ also found no difference in current smoking or alcohol use 
Table 4 OR and $95 \% \mathrm{Cl}$ for selected health behaviours in cancer survivors $v$. persons without cancer at baseline in the Multiethnic Cohort Study

\begin{tabular}{|c|c|c|c|c|c|c|c|c|}
\hline \multirow[b]{2}{*}{ Total number of cases } & \multicolumn{2}{|c|}{ Any site ( $n 16346)$} & \multicolumn{2}{|c|}{ Colorectal cancer ( $n$ 1741) } & \multicolumn{2}{|c|}{ Breast cancer $(n 3436)^{*}$} & \multicolumn{2}{|c|}{ Prostate cancer ( $n$ 2407) } \\
\hline & OR & $95 \% \mathrm{Cl}$ & OR & $95 \% \mathrm{Cl}$ & OR & $95 \% \mathrm{Cl}$ & OR & $95 \% \mathrm{Cl}$ \\
\hline WCRF/AICR recommendationst & 0.97 & $0.96,0.99$ & 0.93 & $0.89,0.97$ & $1 \cdot 00$ & $0.97,1.03$ & $1 \cdot 04$ & $1.00,1.08$ \\
\hline Dietary recommendationst & 0.99 & $0.98,1.01$ & 0.97 & $0.94,1.01$ & $1 \cdot 05$ & $1 \cdot 02,1 \cdot 08$ & 1.04 & $1 \cdot 01,1.07$ \\
\hline \multicolumn{9}{|l|}{ BMI $\left(\mathrm{kg} / \mathrm{m}^{2}\right) \dagger$} \\
\hline Underweight & $1 \cdot 28$ & $1 \cdot 15,1 \cdot 42$ & $1 \cdot 29$ & $0.95,1 \cdot 75$ & $1 \cdot 01$ & $0 \cdot 82,1 \cdot 23$ & $0 \cdot 84$ & $0.53,1 \cdot 33$ \\
\hline Normal weight & $1 \cdot 00$ & Ref. & $1 \cdot 00$ & Ref. & 1.00 & Ref. & 1.00 & Ref. \\
\hline Overweight & 0.96 & $0.93,1 \cdot 00$ & $1 \cdot 11$ & $1 \cdot 00,1 \cdot 24$ & 1.06 & $0 \cdot 97,1 \cdot 15$ & 0.99 & $0.90,1.09$ \\
\hline Obese & $1 \cdot 02$ & $0.97,1.07$ & $1 \cdot 18$ & $1 \cdot 02,1 \cdot 36$ & 1.06 & $0 \cdot 96,1 \cdot 17$ & 0.96 & $0.84,1.09$ \\
\hline \multicolumn{9}{|l|}{ Smoking status } \\
\hline Never smoker & $1 \cdot 00$ & Ref. & $1 \cdot 00$ & Ref. & $1 \cdot 00$ & Ref. & 1.00 & Ref. \\
\hline Former smoker & $1 \cdot 22$ & $1 \cdot 18,1 \cdot 27$ & $1 \cdot 21$ & $1 \cdot 08,1 \cdot 35$ & $1 \cdot 10$ & $1 \cdot 02,1 \cdot 19$ & 0.87 & $0.79,0.95$ \\
\hline Current smoker & $1 \cdot 00$ & $0.95,1.06$ & 0.97 & $0 \cdot 82,1 \cdot 13$ & $0 \cdot 77$ & $0.69,0.87$ & 0.72 & $0.63,0.82$ \\
\hline \multicolumn{9}{|l|}{ Alcohol } \\
\hline Not meeting WCRF/AICR recommendation‡ & $1 \cdot 00$ & Ref. & $1 \cdot 00$ & Ref. & $1 \cdot 00$ & Ref. & $1 \cdot 00$ & Ref. \\
\hline Meeting recommendation§ & 1.02 & $0.97,1 \cdot 07$ & $0 \cdot 91$ & $0 \cdot 82,1 \cdot 00$ & 0.98 & $0 \cdot 87,1 \cdot 11$ & $1 \cdot 33$ & $1 \cdot 17,1 \cdot 51$ \\
\hline \multicolumn{9}{|l|}{ Physical activity } \\
\hline Not meeting WCRF/AICR recommendation‡ & 1.00 & Ref. & $1 \cdot 00$ & Ref. & $1 \cdot 00$ & Ref. & $1 \cdot 00$ & Ref. \\
\hline Meeting recommendation $\|$ & $0 \cdot 85$ & $0 \cdot 82,0 \cdot 88$ & $0 \cdot 81$ & $0.74,0.90$ & $0 \cdot 90$ & $0.84,0.96$ & $0 \cdot 90$ & $0.82,0.98$ \\
\hline \multicolumn{9}{|l|}{ Diet } \\
\hline \multicolumn{9}{|l|}{ Fruit and vegetables $(\mathrm{g} / \mathrm{d}) \ddagger$} \\
\hline$<400$ & $1 \cdot 00$ & Ref. & $1 \cdot 00$ & Ref. & $1 \cdot 00$ & Ref. & $1 \cdot 00$ & Ref. \\
\hline$\geq 400$ & $1 \cdot 00$ & $0.97,1.04$ & $1 \cdot 00$ & $0 \cdot 89,1 \cdot 11$ & 1.04 & $0.96,1 \cdot 13$ & 1.05 & $0 \cdot 96,1 \cdot 16$ \\
\hline \multicolumn{9}{|l|}{ Red meat (g/week) } \\
\hline$\geq 500 \ddagger$ & $1 \cdot 00$ & Ref. & $1 \cdot 00$ & Ref. & $1 \cdot 00$ & Ref. & $1 \cdot 00$ & Ref. \\
\hline$<500$ & 1.03 & $0.99,1.08$ & $1 \cdot 02$ & $0 \cdot 91,1 \cdot 14$ & $1 \cdot 11$ & $1 \cdot 01,1 \cdot 22$ & $1 \cdot 12$ & $1 \cdot 02,1 \cdot 23$ \\
\hline \multicolumn{9}{|l|}{$\mathrm{Na}(\mathrm{g} / \mathrm{d})$} \\
\hline$\geq 2 \cdot 4 \ddagger$ & $1 \cdot 00$ & Ref. & $1 \cdot 00$ & Ref. & $1 \cdot 00$ & Ref. & $1 \cdot 00$ & Ref. \\
\hline$<2 \cdot 4$ & 0.99 & $0.96,1.02$ & 0.98 & $0 \cdot 88,1 \cdot 08$ & $1 \cdot 08$ & $1 \cdot 01,1 \cdot 16$ & $1 \cdot 00$ & $0.91,1.09$ \\
\hline \multicolumn{9}{|l|}{ Dietary fibre $(\mathrm{g} / \mathrm{d})$} \\
\hline$<25 \ddagger$ & $1 \cdot 00$ & Ref. & $1 \cdot 00$ & Ref. & $1 \cdot 00$ & Ref. & $1 \cdot 00$ & Ref. \\
\hline$\geq 25$ & $1 \cdot 00$ & $0.97,1.03$ & $0 \cdot 91$ & $0 \cdot 83,1 \cdot 01$ & 1.06 & $0.99,1 \cdot 14$ & 1.09 & $1 \cdot 00,1 \cdot 18$ \\
\hline \multicolumn{9}{|l|}{$\%$ Energy from fat } \\
\hline$\geq 30 \ddagger$ & $1 \cdot 00$ & Ref. & $1 \cdot 00$ & Ref. & $1 \cdot 00$ & Ref. & $1 \cdot 00$ & Ref. \\
\hline$<30$ & 0.97 & $0.94,1.00$ & 0.95 & $0 \cdot 86,1 \cdot 05$ & $1 \cdot 10$ & $1 \cdot 02,1 \cdot 18$ & $1 \cdot 03$ & $0.95,1.13$ \\
\hline \multicolumn{9}{|l|}{$\%$ Energy from saturated fat } \\
\hline$\geq 10 \ddagger$ & $1 \cdot 00$ & Ref. & $1 \cdot 00$ & Ref. & $1 \cdot 00$ & Ref. & $1 \cdot 00$ & Ref. \\
\hline$<10$ & 0.95 & $0.92,0.99$ & 0.94 & $0.84,1 \cdot 05$ & $1 \cdot 11$ & $1 \cdot 02,1 \cdot 20$ & 1.09 & $1 \cdot 00,1 \cdot 20$ \\
\hline
\end{tabular}

WCRF/AICR, World Cancer Research Fund/American Institute for Cancer Research; Ref., reference category. ${ }^{\star}$ Analysis included only females.

tAdjusted for age, ethnicity, sex and education.

¥Adjusted for age, ethnicity, sex, education and BMI.

\$WCRF/AICR recommendation for those who choose to drink alcohol is $\leq 1$ drink/d for women and $\leq 2$ drinks/d for men.

IWCRF/AICR physical activity recommendation is to engage in at least $30 \mathrm{~min}$ of moderate or vigorous physical activity per day. 
Table $5 \mathrm{OR}$ and $95 \% \mathrm{Cl}$ by ethnicity for selected health behaviours in cancer survivors (any site) v. persons without cancer at baseline in the Multiethnic Cohort Study

\begin{tabular}{|c|c|c|c|c|c|c|c|c|c|c|c|}
\hline \multirow[b]{2}{*}{ Total number of cases } & \multicolumn{2}{|c|}{ White ( $n$ 5269) } & \multicolumn{2}{|c|}{ African American ( $n$ 3135) } & \multicolumn{2}{|c|}{ Native Hawaiian ( $n$ 1094) } & \multicolumn{2}{|c|}{ Japanese American ( $n$ 4152) } & \multicolumn{2}{|c|}{ Latino $(n$ 2696) } & \multirow[b]{2}{*}{$P$ value $^{*}$} \\
\hline & OR & $95 \% \mathrm{Cl}$ & OR & $95 \% \mathrm{Cl}$ & OR & $95 \% \mathrm{Cl}$ & OR & $95 \% \mathrm{Cl}$ & OR & $95 \% \mathrm{Cl}$ & \\
\hline WCRF/AICR recommendationst & 0.97 & $0.95,1.00$ & 0.98 & $0.95,1.02$ & 0.96 & $0.91,1.02$ & 0.98 & $0.95,1.01$ & 0.95 & $0.92,0.99$ & $0 \cdot 64$ \\
\hline \multicolumn{12}{|l|}{ BMI $\left(\mathrm{kg} / \mathrm{m}^{2}\right) \dagger$} \\
\hline Underweight & $1 \cdot 29$ & $1.06,1.56$ & $1 \cdot 37$ & $0.99,1.88$ & $1 \cdot 61$ & $0.97,2.68$ & $1 \cdot 19$ & $1 \cdot 02,1 \cdot 39$ & $1 \cdot 49$ & $0.99,2.24$ & $0 \cdot 12$ \\
\hline Normal weight & 1.00 & Ref. & $1 \cdot 00$ & Ref. & $1 \cdot 00$ & Ref. & $1 \cdot 00$ & Ref. & 1.00 & Ref. & \\
\hline Overweight & 0.99 & $0.93,1.06$ & 0.91 & $0.83,1 \cdot 00$ & 0.89 & $0.76,1.04$ & 0.97 & $0.90,1.05$ & $1 \cdot 02$ & $0.93,1.12$ & \\
\hline Obese & 1.09 & $1 \cdot 00,1 \cdot 18$ & 0.95 & $0.86,1 \cdot 05$ & 1.08 & $0.92,1 \cdot 26$ & 1.08 & $0.94,1 \cdot 24$ & 1.03 & $0.92,1 \cdot 15$ & \\
\hline \multicolumn{12}{|l|}{ Smoking statusł } \\
\hline Never smoker & $1 \cdot 00$ & Ref. & 1.00 & Ref. & 1.00 & Ref. & 1.00 & Ref. & $1 \cdot 00$ & Ref. & \\
\hline Former smoker & $1 \cdot 17$ & $1 \cdot 10,1 \cdot 25$ & $1 \cdot 28$ & $1 \cdot 17,1 \cdot 39$ & $1 \cdot 31$ & $1 \cdot 14,1 \cdot 51$ & $1 \cdot 31$ & $1 \cdot 22,1 \cdot 41$ & $1 \cdot 22$ & $1 \cdot 12,1 \cdot 34$ & $<0 \cdot 01$ \\
\hline Current smoker & 1.07 & $0 \cdot 98,1 \cdot 17$ & $1 \cdot 11$ & $1 \cdot 00,1 \cdot 24$ & 1.05 & $0 \cdot 88,1 \cdot 26$ & 0.85 & $0.75,0.96$ & 0.88 & $0.77,1 \cdot 00$ & \\
\hline \multicolumn{12}{|l|}{ Alcohol } \\
\hline Not meeting WCRF/AICR recommendation & $1 \cdot 00$ & Ref. & 1.00 & Ref. & 1.00 & Ref. & $1 \cdot 00$ & Ref. & $1 \cdot 00$ & Ref. & \\
\hline Meeting recommendation§ & 0.93 & $0.86,0.99$ & $1 \cdot 21$ & $1 \cdot 06,1 \cdot 39$ & 0.96 & $0 \cdot 79,1 \cdot 17$ & $1 \cdot 14$ & $1 \cdot 00,1 \cdot 29$ & 1.04 & $0.90,1 \cdot 20$ & $<0 \cdot 01$ \\
\hline \multicolumn{12}{|l|}{ Physical activity } \\
\hline Not meeting WCRF/AICR recommendation & $1 \cdot 00$ & Ref. & $1 \cdot 00$ & Ref. & $1 \cdot 00$ & Ref. & $1 \cdot 00$ & Ref. & $1 \cdot 00$ & Ref. & \\
\hline Meeting recommendation $\|$ & $0 \cdot 89$ & $0.83,0.94$ & $0 \cdot 84$ & $0.78,0.91$ & $0 \cdot 73$ & $0.64,0.83$ & 0.87 & $0.81,0.92$ & $0 \cdot 85$ & $0.78,0.92$ & 0.04 \\
\hline \multicolumn{12}{|l|}{ Diet } \\
\hline \multicolumn{12}{|l|}{ Fruit and vegetables (g/d) } \\
\hline$<400 \ddagger$ & $1 \cdot 00$ & Ref. & $1 \cdot 00$ & Ref. & 1.00 & Ref. & 1.00 & Ref. & $1 \cdot 00$ & Ref. & \\
\hline$\geq 400$ & 0.98 & $0.91,1.04$ & 0.96 & $0.89,1.04$ & 1.01 & $0 \cdot 87,1 \cdot 17$ & 1.07 & $0.99,1 \cdot 16$ & 1.04 & $0.95,1.15$ & $0 \cdot 10$ \\
\hline \multicolumn{12}{|l|}{ Red meat (g/week) } \\
\hline$\geq 500 \ddagger$ & 1.00 & Ref. & $1 \cdot 00$ & Ref. & 1.00 & Ref. & 1.00 & Ref. & 1.00 & Ref. & \\
\hline$<500$ & 1.06 & $0.99,1 \cdot 15$ & 1.09 & $1 \cdot 00,1 \cdot 19$ & $1 \cdot 11$ & $0.98,1 \cdot 27$ & 0.98 & $0.91,1.07$ & 0.98 & $0.90,1.07$ & 0.53 \\
\hline \multicolumn{12}{|l|}{$\mathrm{Na}(\mathrm{g} / \mathrm{d})$} \\
\hline$\geq 2 \cdot 4 \ddagger$ & $1 \cdot 00$ & Ref. & 1.00 & Ref. & $1 \cdot 00$ & Ref. & $1 \cdot 00$ & Ref. & 1.00 & Ref. & \\
\hline$<2 \cdot 4$ & 1.04 & $0 \cdot 97,1 \cdot 10$ & 0.96 & $0.89,1.03$ & 1.03 & $0 \cdot 89,1 \cdot 18$ & 1.00 & $0.93,1.07$ & 0.93 & $0.85,1.02$ & $0 \cdot 10$ \\
\hline \multicolumn{12}{|l|}{ Dietary fibre $(g / d)$} \\
\hline$<25 \ddagger$ & $1 \cdot 00$ & Ref. & $1 \cdot 00$ & Ref. & $1 \cdot 00$ & Ref. & $1 \cdot 00$ & Ref. & 1.00 & Ref. & \\
\hline$\geq 25$ & 0.96 & $0.90,1.02$ & 0.98 & $0.91,1.06$ & 1.01 & $0.89,1 \cdot 15$ & $1 \cdot 10$ & $1 \cdot 03,1 \cdot 17$ & 0.97 & $0.90,1.05$ & 0.03 \\
\hline \multicolumn{12}{|l|}{$\%$ Energy from fat } \\
\hline$\geq 30 \ddagger$ & $1 \cdot 00$ & Ref. & $1 \cdot 00$ & Ref. & 1.00 & Ref. & $1 \cdot 00$ & Ref. & 1.00 & Ref. & \\
\hline$<30$ & $1 \cdot 02$ & $0.96,1.08$ & $0 \cdot 89$ & $0.83,0.97$ & 0.91 & $0 \cdot 80,1 \cdot 03$ & $1 \cdot 01$ & $0.94,1.08$ & 0.97 & $0 \cdot 89,1 \cdot 05$ & 0.01 \\
\hline \multicolumn{12}{|l|}{$\%$ Eneray from saturated fat } \\
\hline$\geq 10 \ddagger$ & $1 \cdot 00$ & Ref. & 1.00 & Ref. & 1.00 & Ref. & 1.00 & Ref. & $1 \cdot 00$ & Ref. & \\
\hline$<10$ & 0.99 & $0.93,1.05$ & 0.93 & $0 \cdot 86,1 \cdot 00$ & $0 \cdot 89$ & $0 \cdot 78,1 \cdot 03$ & 0.98 & $0.88,1.09$ & 0.96 & $0 \cdot 89,1 \cdot 04$ & 0.25 \\
\hline
\end{tabular}

WCRF/AICR, World Cancer Research Fund/American Institute for Cancer Research; Ref., reference category.

${ }^{*} P$ value refers to test of heterogeneity for the effect of health behaviours across ethnic groups.

tAdjusted for age, sex and education.

tAdjusted for age, sex, education and BMI.

SWCRF/AICR recommendation for those who choose to drink alcohol is $\leq 1 \mathrm{drink} / \mathrm{d}$ for women and $\leq 2$ drinks/d for men.

IWCRF/AICR physical activity recommendation is to engage in at least $30 \mathrm{~min}$ of moderate or vigorous physical activity per day. 
between cancer survivors and non-cancer controls; however, in contrast to the present study and previous findings ${ }^{(13)}$, reported survivors were more likely (9\%) to engage in physical activity when combining data from the 1998-2001 NHIS. Mayer et al. ${ }^{(16)}$ found no differences in BMI, physical activity, current smoking or fruit and vegetable consumption between cancer survivors and the general population in the National Cancer Institute's 2003 Health Information National Trends Survey. Rogers et $a l^{(15)}$ examining prostate cancer survivors surveyed in the 2002 Behavioral Risk Factor Surveillance System reported results similar to ours for BMI, but in contrast found that survivors were more likely to consume fruit and vegetables but not to differ in current smoking or alcohol consumption. Our finding that cancer survivors were less likely to engage in physical activity has been observed in only one other study and was restricted to participants 40-64 years of age ${ }^{(13)}$. Discrepancies in the findings among studies may reflect such factors as differences in the distributions of cancers, differences in analytical approaches and differences in the age distributions of study samples.

The fact that a diagnosis of cancer was not associated with meaningful differences in the behavioural risk factors for cancer is of concern, given the higher risk of cancer and other chronic diseases for cancer survivors. Although evidence directly linking health behaviours in cancer survivors to reductions in disease is limited, improvements in these behaviours are likely to be of benefit in this population. However, as previously discussed ${ }^{(13)}$, improvements in modifiable health behaviours may be of less relevance among those with advanced disease or poorer prognosis, with changes in certain behaviours more or less beneficial for specific cancers. Further studies examining behaviour change within individuals after a diagnosis of cancer $^{(20-22)}$ with sufficient follow-up time are needed to examine the impact of specific behaviours on subsequent disease risk more comprehensively.

Strengths of the present study include: (i) the representativeness of the study population; (ii) the large number of cases; (iii) stratification by cancer site and ethnicity; (iv) the ethnic diversity of the sample and novel findings among Native Hawaiian, Japanese-Americans and Latino cancer survivors; (v) registry confirmation of cases and analyses demonstrating similar results for cases identified by questionnaire or registry; and (vi) detailed dietary information. There were some limitations as well. First, all data on health behaviours were obtained from self-report collected after a diagnosis of cancer and were thus subject to potential recall bias. In addition, the QFFQ has been found to rank individuals well on dietary factors, but has not been validated for identification of individuals meeting dietary recommendations. However, the accuracy would be expected to be similar for cancer survivors and others. Second, the cross-sectional nature of the present study prevents any ability to assess changes in behaviours over time. Because the health behaviours examined are thought to be risk factors for disease, small differences in these behaviours may be indiscernible if they were engaged in less frequently by survivors before their diagnosis of disease. Third, data utilized in the present study examined patterns of behaviour between 1993 and 1996 and, therefore, may not reflect current behaviours. Fourth, for some comparisons, the large sample size could possibly detect as significant those findings that are unimportant clinically.

In conclusion, cancer survivors do not appear to differ from the general population with respect to meeting recommendations regarding diet, physical activity, smoking, alcohol consumption or BMI, despite their increased risk of disease. Treatment practices for cancer survivors, with a more focused approach on behaviour modification during the post-treatment period in order to capitalize on the 'teachable moment', as well as follow-up programmes aimed at behavioural maintenance, may assist cancer survivors to achieve improved health-related behaviours. Additional longitudinal studies are needed to determine the extent to which cancer survivors are engaging in longterm behaviour modification, and whether subsequent changes translate into a reduced risk of disease.

\section{Acknowledgements}

The Multiethnic Cohort Study has been supported by Grant no. R37 CA 54281 from the National Cancer Institute. The tumour registries are supported by $\mathrm{NCI}$ contracts N01-PC-35137 and N01-PC-35139. N.J.O. was supported by a post-doctoral fellowship on Grant no. R25 CA 90956. The authors have no conflict of interest to declare. N.J.O. designed and carried out the statistical analysis, interpreted results and wrote the manuscript; G.M. originally conceived of the analysis and helped with the analytic strategy and interpretation of results; L.R.W. provided expertise pertaining to analytic strategy, statistical analysis and interpretation of results; L.N.K. provided insight into the analytic strategy and interpretation of results. All authors provided feedback on the initial draft of the manuscript and approved the final version. The authors thank all participants in the Multiethnic Cohort Study.

\section{References}

1. Rowland J, Mariotto A, Aziz N et al. (2004) Cancer survivorship - United States, 1971-2001. MMWR Morb Mortal Wkly Rep 53, 526-529.

2. Demark-Wahnefried W, Aziz NM, Rowland JH et al. (2005) Riding the crest of the teachable moment: promoting longterm health after the diagnosis of cancer. J Clin Oncol $\mathbf{2 3}$, 5814-5830.

3. Brown BW, Brauner C \& Minnotte MC (1993) Noncancer deaths in white adult cancer patients. J Natl Cancer Inst $\mathbf{8 5}$, 979-987. 
4. World Cancer Research Fund/American Institute for Cancer Research (2007) Food, Nutrition, Physical Activity, and the Prevention of Cancer: A Global Perspective. Washington, DC: AICR.

5. Doyle C, Kushi LH, Byers T et al. (2006) Nutrition and physical activity during and after cancer treatment: an American Cancer Society guide for informed choices. $C A$ Cancer J Clin 56, 323-353.

6. Kushi LH, Byers T, Doyle C et al. (2006) American Cancer Society guidelines on nutrition and physical activity for cancer prevention: reducing the risk of cancer with healthy food choices and physical activity. CA Cancer J Clin 56, 254-281.

7. American Cancer Society (2009) Cancer Facts \& Figures 2009. Atlanta, GA: ACS.

8. Blanchard CM, Denniston MM, Baker F et al. (2003) Do adults change their lifestyle behaviors after a cancer diagnosis? Am J Health Behav 27, 246-256.

9. Maskarinec G, Murphy S, Shumay DM et al. (2001) Dietary changes among cancer survivors. Eur J Cancer Care (Engl) 10, 12-20.

10. Patterson RE, Neuhouser ML, Hedderson MM et al. (2003) Changes in diet, physical activity, and supplement use among adults diagnosed with cancer. J Am Diet Assoc 103, 323-328.

11. Evangelista LS, Sarna L, Brecht ML et al. (2003) Health perceptions and risk behaviors of lung cancer survivors. Heart Lung 32, 131-139.

12. Maunsell E, Drolet M, Brisson J et al. (2002) Dietary change after breast cancer: extent, predictors, and relation with psychological distress. J Clin Oncol 20, 1017-1025.

13. Coups EJ \& Ostroff JS (2005) A population-based estimate of the prevalence of behavioral risk factors among adult cancer survivors and noncancer controls. Prev Med 40, 702-711.
14. Bellizzi KM, Rowland JH, Jeffery DD et al. (2005) Health behaviors of cancer survivors: examining opportunities for cancer control intervention. J Clin Oncol 23, 8884-8893.

15. Rogers LQ, Courneya KS, Paragi-Gururaja R et al. (2008) Lifestyle behaviors, obesity, and perceived health among men with and without a diagnosis of prostate cancer: a population-based, cross-sectional study. BMC Public Health 8, 23.

16. Mayer DK, Terrin NC, Menon U et al. (2007) Health behaviors in cancer survivors. Oncol Nurs Forum 34, 643-651.

17. Kolonel LN, Henderson BE, Hankin JH et al. (2000) A multiethnic cohort in Hawaii and Los Angeles: baseline characteristics. Am J Epidemiol 151, 346-357.

18. Stram DO, Hankin JH, Wilkens LR et al. (2000) Calibration of the dietary questionnaire for a multiethnic cohort in Hawaii and Los Angeles. Am J Epidemiol 151, 358-370.

19. US Department of Health and Human Services \& US Department of Agriculture (2005) Dietary Guidelines for Americans 2005, 6th ed. Washington, DC: US Government Printing Office.

20. Satia JA, Campbell MK, Galanko JA et al. (2004) Longitudinal changes in lifestyle behaviors and health status in colon cancer survivors. Cancer Epidemiol Biomarkers Prev 13, 1022-1031.

21. Caan B, Sternfeld B, Gunderson E et al. (2005) Life After Cancer Epidemiology (LACE) Study: a cohort of early stage breast cancer survivors (United States). Cancer Causes Control 16, 545-556.

22. Tangney CC, Young JA, Murtaugh MA et al. (2002) Selfreported dietary habits, overall dietary quality and symptomatology of breast cancer survivors: a cross-sectional examination. Breast Cancer Res Treat 71, 113-123. 